\title{
Nuptial feeding and genital coupling of Neopanorpa scorpionflies (Insecta: Mecoptera: Panorpidae) with notal organs of various lengths
}

\author{
Xin Tong \\ Key Laboratory of Plant Protection Resources and Pest Management, Ministry of Education, \\ College of Plant Protection, Northwest A\&F University, Yangling, Shaanxi 712100, China
}

\begin{abstract}
Bao-Zhen Hua
Key Laboratory of Plant Protection Resources and Pest Management, Ministry of Education, College of Plant Protection, Northwest A\&F University, Yangling, Shaanxi 712100, China huabzh@nwafu.edu.cn
\end{abstract}

\begin{abstract}
Neopanorpa, the second largest genus in Panorpidae, is mainly characterized by the well-developed notal organ on male tergum III. However, it remains largely unknown how the length of the notal organ influences the nuptial feeding behaviour of Neopanorpa. Here, we investigated the nuptial feeding by comparing the morphology of mating-related structures and the genital coupling of a) Neopanorpa lui Chou \& Ran, 1981 with a weakly-developed notal organ, b) N. carpenteri Cheng, 1957 with a medium-sized notal organ, and c) $N$. longiprocessa Hua \& Chou, 1997 with an extremely elongated notal organ. The couples of $N$. lui and $N$. carpenteri maintain an intermittent mouth-to-mouth mode but do not exchange any edible food. After that the males secrete a salivary mass onto the surface as a nuptial gift, which is distinctly larger in $N$. carpenteri than in $N$. lui. Correspondingly, the male salivary glands are more developed in $N$. carpenteri than in $N$. lui. Males of $N$. longiprocessa bear very short salivary glands corresponding to a coercive mating tactic. The genital couplings are similar among the three species of Neopanorpa. The paired hypovalves of males are used to control the cerci of females. The prominent basal processes of male gonostyli grasp the posterior portion of the female medigynium across the intersegmental membrane. The male aedeagus physically couples with the female medigynium to ensure the male phallotreme to connect to the female copulatory pore. The influence of the notal organ length on the nuptial feeding behaviour of Neopanorpa is briefly discussed.
\end{abstract}

\section{Keywords}

copulation - copulatory mechanism - mating behaviour - nuptial gift - scorpionfly 


\section{Introduction}

Nuptial feeding is an interesting behaviour in animal mating systems and is a bridge to connect the resources between a male and a female (Thornhill \& Alcock, 1983; Boggs, 1990). Most nuptial gifts are provided by the male and exhibit multitudinous forms such as glandular secretions, preys, and even the body parts (Vahed, 1998; Lewis \& South, 2012). In general, the edible gifts are predicted to help the males attract a female, reduce the female resistance, and prolong the copulation duration to increase the quantity of sperm transferred (Vahed, 1998; Gwynne, 2008; Lewis \& South, 2012; Vahed et al., 2014). Notably, the gift-giving behaviour shows surprising plasticity among insect groups (Vahed, 1998; Preston-Mafham, 1999; Stutt \& Siva-Jothy, 2001; Lehmann, 2012; Lewis \& South, 2012), including Panorpidae (Insecta: Mecoptera) (Thornhill, 1981; Sauer et al., 1998; Engqvist, 2007).

Panorpidae usually attract the interests of entomologists for their diverse courtships and nuptial feeding behaviours (Thornhill, 1980, 1981; Thornhill \& Sauer, 1991; Sauer et al., 1998; Zhong \& Hua, 2013b). The genus Panorpa Linnaeus, $175^{8}$ is often treated as the model animal to investigate the mating systems of insects because most males of Panorpa can alternatively provide salivary secretions or preys as a nuptial gift according to their nutritional state (Byers \& Thornhill, 1983; Engles \& Sauer, 2006; Engqvist, 2007, 2009). Males of several Asian species of Panorpa, however, only provide a prey prior to copulation (Thornhill, 1992; Ma \& Hua, 2011b). Males of Cerapanorpa Gao, Ma \& Hua, 2016 and Dicerapanorpa Zhong \& Hua, 2013 provide one or two salivary masses (Zhong et al., 2015a; Tong et al., 2018), whereas the males of Furcatopanorpa Ma \& Hua, 2011 continuously provide liquid salivary secretions through a mouth-to-mouth mode (Zhong et al., 2015b).
Salivary glands are the structure of male scorpionflies to produce salivary secretions (Byers \& Thornhill, 1983; Ma et al., 2011). The salivary glands of male $P$. liui Hua, 1997 are a short bifurcated structure, thereby unable for the males to offer a salivary mass. The male instead provides a prey to the female as a nuptial gift (Ma \& Hua, 2011b; Ma et al., 2011). The salivary glands of $D$. magna (Chou, 1981) are welldeveloped and octofurcated, so that the males can secrete another salivary mass as a nuptial gift when the first mass is lost (Ma et al., 2011; Zhong et al., 2015a). The hexafurcated secretory tubes are extremely elongated for male P. vulgaris Imhoff \& Labram, 1836 , which can provide multiple salivary masses to the female (Potter, 1938; Sauer et al., 1998). The salivary glands of $F$. longihypovalva even branch twice in a dichotomous way to form 24 distal secretory tubules to support the males to continuously provide liquid salivary secretions during copulation (Zhong et al., 2015b). Based on the morphology of salivary glands, we are able to estimate the ability of male scorpionflies to secrete salivary secretions as a nuptial gift.

Nuptial feeding behaviour is also greatly associated with the grasping structures of male scorpionflies, especially the notal organ. The notal organ, a clamp-like process on the posterior margin of male tergite III, is used to seize the anterior edge of the female's wings from one side (Mickoleit, 1971; Thornhill \& Sauer, 1991; Kock et al., 2009; Krzemiński \& Soszynska-Maj, 2012). The male of F. longihypovalva continuously provides salivary secretions to the male. This behaviour is believed to be related to the male lacking a notal organ to control the female (Zhong et al., 2015b). In $P$. vulgaris the notal organ is regarded helpful to prolong copulation and to obtain a coercive mating (Thornhill \& Sauer, 1991). Although Kock et al. (2009) contend the view that the notal organ does not prolong the copulation duration, there is no doubt that 
the notal organ can enhance male control of copulation and benefit the male scorpionflies to save the nuptial gift. The male of Neopanorpa longiprocessa Hua \& Chou, 1997 bears an extremely elongated notal organ that extends to the posterior portion of the fifth abdominal segment. Owing to the firm grasping of the notal organ, $N$. longiprocessa males even no longer need to provide any edible gift during the mating process (Zhong \& Hua, 2013b).

Neopanorpa van der Weele, 1909, the second largest genus of Panorpidae with over 170 species, is mainly characterized by the bifurcated salivary glands and the notal organ more developed than in other genera of Panorpidae (Cai \& Hua, 2008; Ma \& Hua, 2011a; Ma et al., 2011; Zhong \& Hua, 2013a; Gao et al., 2016; Wang \& Hua, 2018a, b). However, how these associated structures influence the nuptial feeding and mating behaviours of Neopanor$p a$ has not been satisfactorily clarified.

In Neopanorpa only $N$. longiprocessa has been reported for the mating behaviour (Zhong \& Hua, 2013b). It is even presumed that all Neopanorpa species adopt the coercive mating tactic because the elongated notal organ can force the female and the simple bifurcated salivary glands lack the ability to secrete a salivary mass (Jiang \& Hua, 2015; Wang \& Hua, 2018b). In fact, not all Neopanor$p a$ males bear an elongated notal organ as in $N$. longiprocessa. The notal organs extend merely to the middle portion of the fourth abdominal segment in the males of most Neopanorpa species, and even only to the anterior portion of the fourth abdominal segment in a few species. It has not been evaluated whether these Neopanorpa males with a moderately or weakly developed notal organ can provide salivary masses as nuptial gifts to the female.

The genitalia of Neopanorpa are distinctively different from those of other genera in Panorpidae (Cai \& Hua, 2008; Ma \& Hua, 2011a; Zhong \& Hua, 2013a; Gao et al., 2016;
Wang \& Hua, 2018a, 2019a). The basal processes on male gonostyli are usually prominent. The hypovalves are elongate and bear two processes. The parameres fused with the aedeagus bear acute lateral processes. The aedeagus is stout, with the paired ventral valves longer than the paired dorsal valves. The female medigynium (or genital plate) is simple with a narrow main plate and a short axis (Wang \& Hua, 2018a, b). However, only $N$. longiprocessa has been described for the copulatory mechanism in this genus based on the male and female genitalia (Zhong \& Hua, $2013 \mathrm{~b})$. The genital coupling during copulation has not been revealed in Neopanorpa.

In this study, we comparatively investigated the courtship, nuptial feeding behaviour, the morphology of mating-related structures, and the genital coupling of a) N. lui Chou \& Ran, 1981 with a weakly-developed notal organ, b) $N$. carpenteri Cheng, 1957 with a medium-sized notal organ, and c) $N$. longiprocessa Hua \& Chou, 1997 with an extremely elongated notal organ, based on the behavioural observation and the freeze-fixed pairs in copula. The influence of the notal organ length on the nuptial feeding behaviour of Neopanorpa is briefly discussed.

\section{Material and methods}

\section{Insect collection}

Adults of $N$. lui and $N$. longiprocessa were collected from the Tiantaishan Forest Park $\left(34^{\circ} 13^{\prime} \mathrm{N}, 106^{\circ} 59^{\prime}\right.$ E, elev. $\left.1500-1800 \mathrm{~m}\right)$ and the Huoditang Forest Park $\left(33^{\circ} 25^{\prime} \mathrm{N}, 108^{\circ} 27^{\prime} \mathrm{E}\right.$, elev. 1500-1700 $\mathrm{m}$ ) in the Qinling Mountains, Shaanxi Province in central China from early June to July of 2017 and 2019. Adults of N. carpenteri were captured from the Yinnashan Forest Park $\left(24^{\circ} 23^{\prime} \mathrm{N}, 116^{\circ} 24^{\prime}\right.$ E, elev. 500-1200 $\mathrm{m})$, Meixian County, Guangdong Province in south China in late April 2018. 


\section{Insect rearing}

The live adults collected were transported to the laboratory and were reared following Thornhill \& Sauer (1991) and Zhong \& Hua $(2013 \mathrm{~b})$. Ten males and 10 females were maintained in a gauze cage $(40 \mathrm{~cm} \times 40 \mathrm{~cm} \times 60$ $\mathrm{cm})$. Each cage was supplied with five dead mealworm larvae (Tenebrio molitor), damp absorbent cotton, and twigs of plants with leaves every day to prevent low nutritional status and simulate the habitat of the adults.

\section{Mating behaviour observation}

Adults of each species were observed $24 \mathrm{~h}$ a day by people who checked the circadian rhythms of mating activities in turn for a week. Then these adults were observed every $30 \mathrm{~min}$ from dawn to midnight or from dusk to dawn to document the courtship behaviour, mating tactic, mating process, mating duration, and the activities of the mating contacted structures. Photographs were taken with a Nikon D710o digital camera. The length of nuptial gifts was estimated based on the photographs.

\section{Freeze-fixation of pairs in copula}

Copulating pairs were frozen through carbon dioxide aerosol spray compressed in hydraulic cans, and were immediately fixed in Carnoy's solution $(100 \%$ ethanol: glacial acetic acid $=3: 1, \mathrm{v} / \mathrm{v}$ ) at room temperature for $24-48$ $\mathrm{h}$ to stabilize the interactions of their genital structures and preserved in $75 \%$ ethanol afterwards (Tong et al., 2017, 2018).

\section{Light microscopy}

Thirty-six live adults (10 males and 10 females of N. lui; 5 males and 5 females of N. longiprocessa; 4 males and 2 females of $N$. carpenteri) were fixed in Dietrich's fluid (formalin: $95 \%$ ethanol: glacial acetic acid: distilled water $=$ 6:15:1:80, $\mathrm{v} / \mathrm{v}$ ) to dissect the salivary glands and genitalia. Photographs were taken with a QImaging Retiga-200oR Fast 1394 Digital Camera attached to the microscope and were stacked with Syncroscopy Auto-Montage software.

For histological observations, freeze-fixed pairs in copula were rinsed six times in $0.1 \mathrm{M}$ phosphate buffered saline ( $\mathrm{pH} 7.2)$ and dehydrated through a graded ethanol series. Then the samples were infiltrated in the mixtures of ethanol and LR White resin (3:1 for $2 \mathrm{~h}, 1: 1$ for $4 \mathrm{~h}$, and 1:3 for $12 \mathrm{~h}$ ), subsequently with pure LR White resin for $24 \mathrm{~h}$ at $18^{\circ} \mathrm{C}$ twice. Finally, the samples were embedded in pure LR White resin and polymerized at $55^{\circ} \mathrm{C}$ for $48 \mathrm{~h}$ (Wang \& Hua, 2018c; Tong \& Hua, 2019).

After complete polymerization, the samples were cut into $1.0 \mu \mathrm{m}$ thick sections with a glass knife on the Leica $\mathrm{EM} \mathrm{UC}_{7}$ ultramicrotome and stained with $0.5 \%$ toluidine blue. The sections were observed and photographed under a Nikon Eclipse 8oi light microscope attached with a Nikon DS-Fil digital camera.

\section{Results}

\section{Courtship and nuptial feeding behaviour}

The mating behaviour of $N$. lui mainly occurs from midnight to dawn. In the initial phase, the male stretches the hypandrium to expose the paired sex pheromone glands and swing the genitalia to emit sex pheromones. The sex pheromones can attract the nearby females as in Panorpa (Engqvist \& Sauer, 2003; Kock et al., 2007). When a female is attracted and approaches the male, he terminates the pheromone emission and moves to one side of the female. At this moment, both sexes stretch their antennae and forelegs to touch each other (fig. 1A), and turn their heads to allow their mouthparts to connect. During this process, the labial and maxillary palps are active (fig. $1 \mathrm{~B}$ ). The whole mouth-tomouth phase can last for several hours. However, the phase is intermittent. Both sexes can 

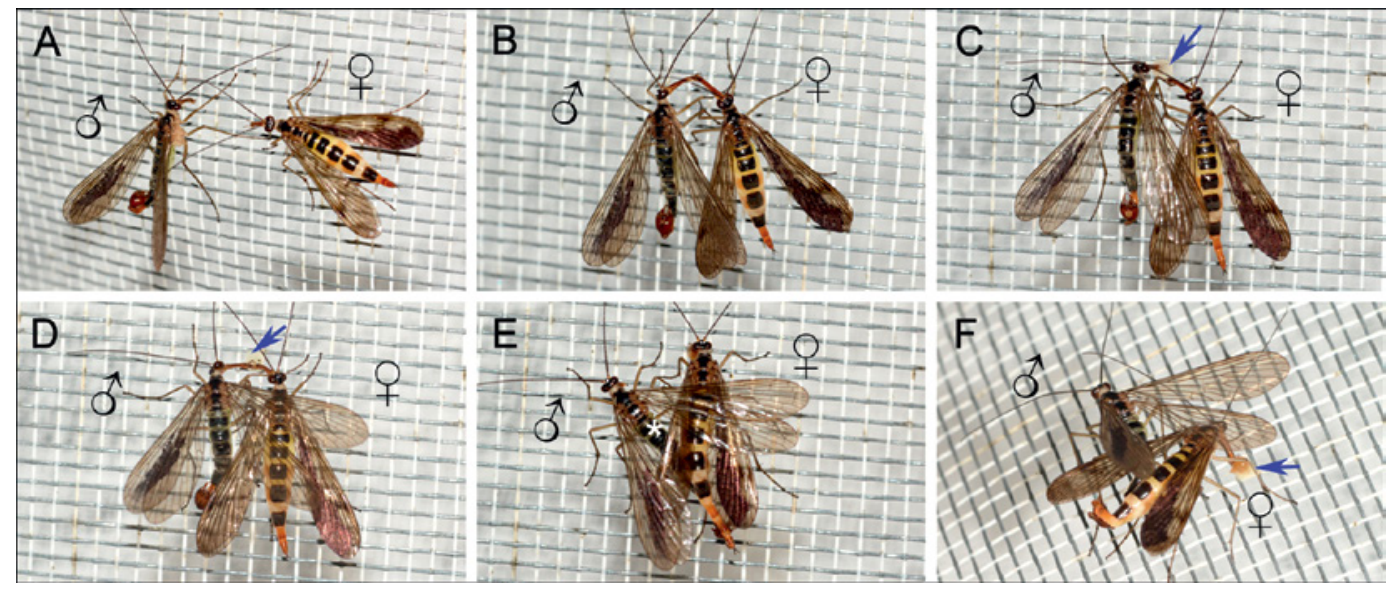

FIGURE 1 Mating process of Neopanorpa lui. A, a male and a female touch each other through the forelegs and antennae; $\mathrm{B}$, the mouthparts of both sexes connect to each other to form a mouth-to-mouth mode; $\mathrm{C}$, the male secretes a salivary mass (arrow); D, the male invites the female to feed on the salivary mass (arrow); E, the female starts to feed on the nuptial gift, the male seizes the female's wing by the notal organ $\left(^{*}\right) ; \mathrm{F}$, the male controls the female and establishes a coupling of genitalia.

tentatively interrupt the connection for several minutes and reestablish connection soon afterwards. In the final phase, the male secretes a small salivary mass $(1.95 \pm 0.69 \mathrm{~mm}$ in length) onto the surface to entice the female to feed on it (figs. $1 \mathrm{C}, \mathrm{D}$ ). When the female begins to feed on the nuptial gift, the male seizes the anterior edge of the female's wings with his notal organ and grasps the female genital segment by his genitalia to establish genital coupling with the female (figs. $1 \mathrm{E}, \mathrm{F}$ ). The copulation lasts for $160 \pm 55 \mathrm{~min}$.

The mating process of $N$. carpenteri is similar to that of N. lui. Males and females of $N$. carpenteri also connect their mouthparts with each other to form a mouth-to-mouth mode (fig. 2A). One to two hours later, the male secretes a huge thick salivary mass $(4.00 \pm$ $0.95 \mathrm{~mm}$ in length) onto the surface as a nuptial gift (figs. $2 \mathrm{~B}-\mathrm{D}$ ). When the female starts to feed on the salivary mass, the male controls the female through the notal organ and establishes genital coupling soon (figs. $2 \mathrm{C}, \mathrm{D}$ ). The copulation duration lasts for $157 \pm 49 \mathrm{~min}$.

The mating behaviour of $N$. longiprocessa occurs any time in a day. No edible food is presented during the mating process. The male tightly grasps the wings of the female for $121 \pm 41$ min to obtain a coercive copulation, which can last for $145 \pm 59 \mathrm{~min}$ (Zhong \& Hua, $2013 \mathrm{~b}$ ). The mouth-to-mouth mode is lacking in $N$. longiprocessa (supplementary fig. $\mathrm{S}_{1}$ ).

\section{Morphology of the salivary glands}

The salivary glands of Neopanorpa mainly consist of a salivary pump, a common salivary duct, and paired salivary tubes.

The salivary glands of $N$. lui are bifurcated and exhibit distinct sexual dimorphism (fig. $3 \mathrm{~A}$ ). In general, the male secretory tube is thin and straight in the anterior portion, thick and convoluted in the middle portion, and gradually constricted in the posterior portion. The salivary glands of male $N$. lui extend to the fifth or sixth abdominal segment.

The salivary glands (fig. ${ }_{3} \mathrm{~B}$ ) of $N$. carpenteri is very similar to those of $N$. lui in gross morphology, but the convoluted middle portion of the male secretory tubes of $N$. carpenteri is longer than those of $N$. lui. Furthermore, the salivary glands of $N$. carpenteri can extend to the sixth abdominal segment. 

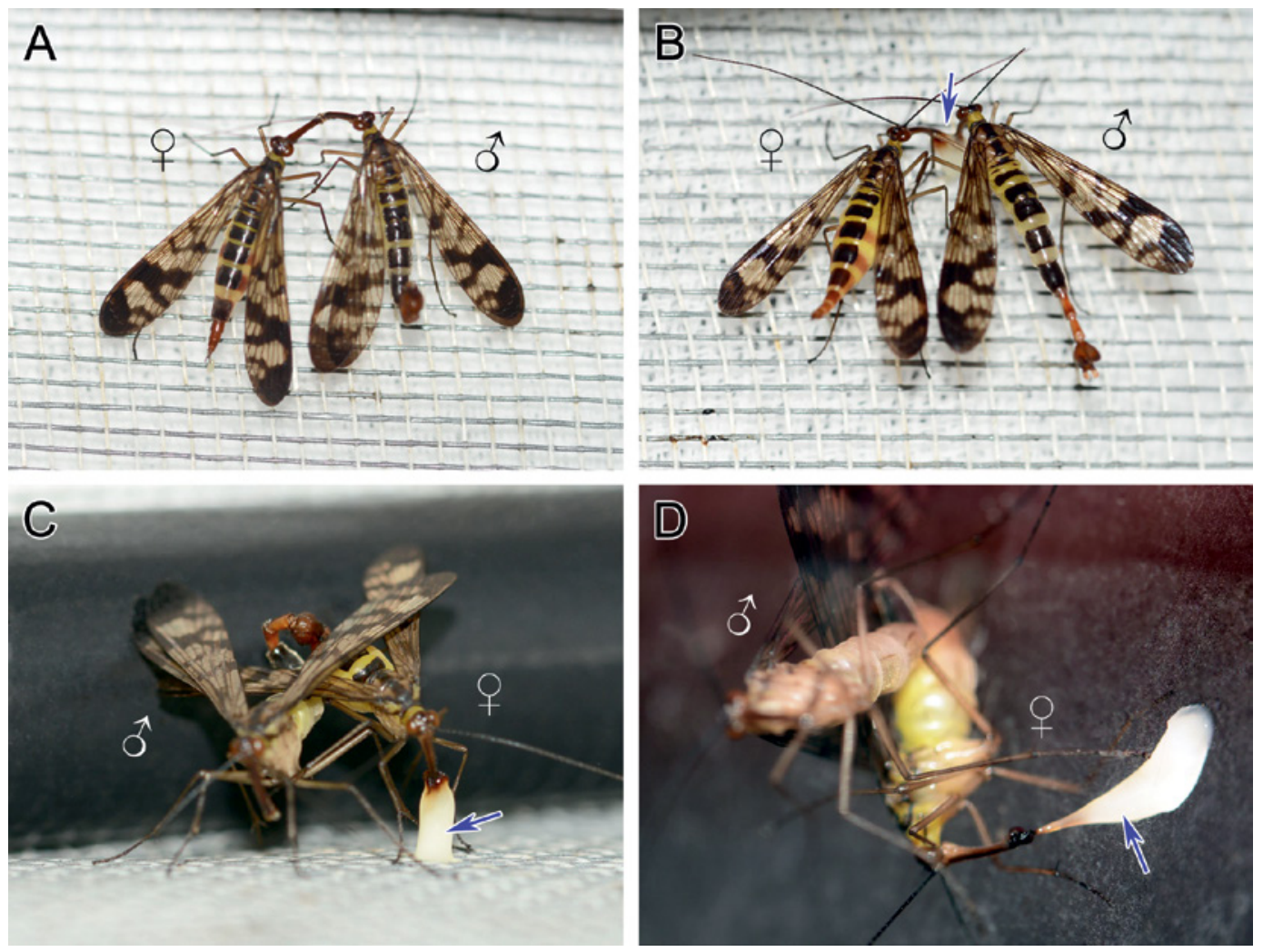

FIGURE 2 Mating process of Neopanorpa carpenteri. A, a male and a female maintain a mouth-to-mouth mode; $\mathrm{B}$, the male secretes a salivary mass (arrow) and invites the female to feed on the nuptial gift; $\mathrm{C}$, the female starts to feed on the salivary mass (arrow), the male establishes the coupling of genitalia; $\mathrm{D}$, the salivary mass (arrow) provided by the male is huge.

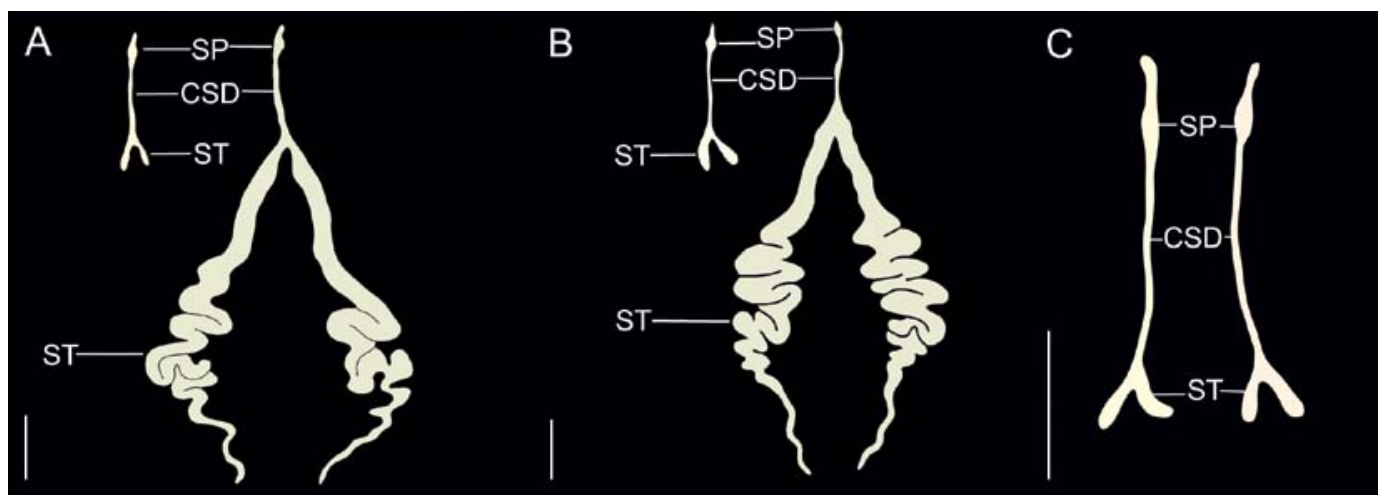

FIGURE 3 Schematic diagram of male and female salivary glands of Neopanorpa (for all, the female salivary glands are situated on the left, the male on the right). A, N. lui; B, N. carpenteri; C, N. longiprocessa. CSD, common salivary duct; SP, salivary pump; ST, secretory tube. Scale bars $=1.0 \mathrm{~mm}$. 
The salivary glands of $N$. longiprocessa are devoid of sexual dimorphism (fig. ${ }_{3} \mathrm{C}$ ). The male salivary glands are simple bifurcated and very short, only extending to the prothorax.

\section{Morphology of the notal organ}

The notal organ on the posterior margin of tergite III functions in cooperation with the postnotal organ on the middle portion of tergite IV. The notal organ is semicircular, extending to the anterior portion of the fourth abdominal segment in N. lui (fig. 4A); is elongate, extending to the middle portion of the fourth abdominal segment in $N$. carpenteri (fig. 4B); and is extremely elongate, extending to the posterior margin of the fifth abdominal segment in $N$. longiprocessa (fig. $4 \mathrm{C}$ ).

\section{Morphology of the genitalia}

The male genitalia of Neopanorpa consist of a dorsal epandrium (tergum IX), a ventral hypandrium (sternum IX), a pair of lateral gonopods, and a median aedeagus. The gonopod consists of a basal gonocoxite and a distal gonostylus. Each gonostylus bears a promi- nent lobe-like basal process and a blunt median tooth. The aedeagus is composed of a pair of ventral valves and a pair of dorsal valves, with a central phallotreme situated between the valves.

In $N$. lui the epandrium is long and broad. The hypandrium consists of a broad basal stalk and a pair of oval hypovalves (supplementary fig. S2). The aedeagus is stout and bears a pair of acute lateral processes. The ventral valves of aedeagus are longer than the dorsal valves (fig. $4 \mathrm{D}$ ).

In $N$. carpenteri the aedeagus is similar to that of $N$. lui (fig. $4 \mathrm{E}$ ). However, the hypovalves are quadrangular, with a pair of distinct sclerotized lateral processes (figs. $5 \mathrm{~A}, \mathrm{~B}$ ). The sex pheromone glands are well-developed (fig. $4 \mathrm{E}$ ).

In $N$. longiprocessa the aedeagus is similar to that of $N$. lui. The hypovalves are oblong, with a pair of distinct blunt dorsad-directing processes (fig. $4 \mathrm{~F}$ ).

Table 1 summarizes differences of mating behaviour and the mating-related structures among three species of Neopanorpa.
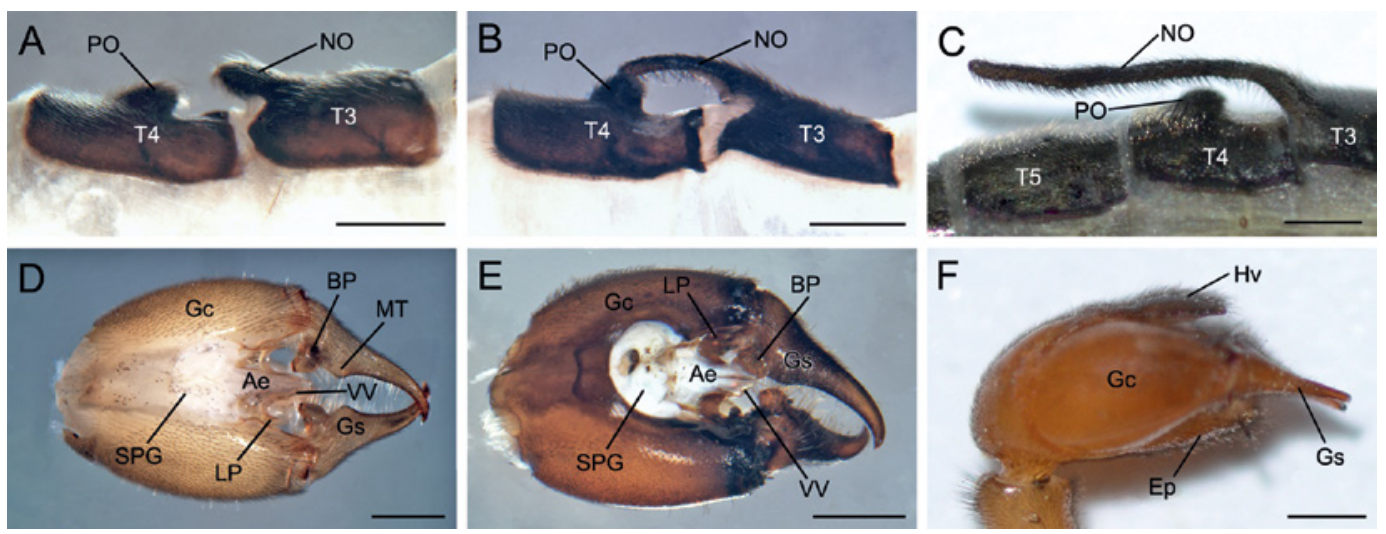

FIGURE 4 Male notal organs and genitalia of Neopanorpa. A, the notal organ of N. lui; B, N. carpenteri; C, $N$. longiprocessa; D, male genitalia of $N$. lui in ventral view with the epandrium and hypandrium removed; E, the same of $N$. carpenteri; F, male genitalia of $N$. longiprocessa in lateral view. Ae, aedeagus; BP, basal process; Ep, epandrium; Gc, gonocoxite; Gs, gonostylus; Hv, hypovalve; LP, lateral process; MT, median tooth; NO, notal organ; PO, postnotal organ; SPG, sex pheromone glands; VV, ventral valve; $\mathrm{T}_{3}-\mathrm{T}_{5}$, tergites III $-\mathrm{V}$. Scale bars $=0.5 \mathrm{~mm}$. 
TABLE 1 Comparisons of mating behaviour and mating-related structures among three species of Neopanorpa

\begin{tabular}{|c|c|c|c|}
\hline & N. lui & N. carpenteri & N. longiprocessa \\
\hline Mating time & From midnight to dawn & From dusk to dawn & Any time in a day \\
\hline Courtship mode & Mouth-to-mouth & Mouth-to-mouth & None \\
\hline $\begin{array}{l}\text { Copulation } \\
\text { duration }\end{array}$ & $160 \pm 55 \mathrm{~min}$ & $157 \pm 49$ min & $145 \pm 59 \mathrm{~min}$ \\
\hline Mating tactic & Nuptial gift providing & Nuptial gift providing & Coercive mating \\
\hline Nuptial gift & $\begin{array}{l}\text { A salivary mass of } 1-2 \mathrm{~mm} \\
\text { in length }\end{array}$ & $\begin{array}{l}\text { A huge salivary mass of } \\
3^{-5} \mathrm{~mm} \text { in length }\end{array}$ & None \\
\hline Salivary glands & Extending to $\mathrm{A}_{5}$ or $\mathrm{A} 6$ & Extending to A6 & Extending to prothorax \\
\hline Notal organ & $\begin{array}{l}\text { Extending to the anterior } \\
\text { portion of } \mathrm{A}_{4}\end{array}$ & $\begin{array}{l}\text { Extending to the middle } \\
\text { portion of } \mathrm{A}_{4}\end{array}$ & $\begin{array}{l}\text { Extending to the } \\
\text { posterior portion of } \mathrm{A}_{5}\end{array}$ \\
\hline Hypovalve & Oblong, without process & $\begin{array}{l}\text { Quadrangular, with } \\
\text { process }\end{array}$ & Oblong, with process \\
\hline
\end{tabular}

\section{Coupling of the male and female genitalia}

The terminal genital ends of male and female $N$. carpenteri tightly couple with each other (figs. 5A, B). The paired hypovalves with sclerotized processes grasp the female cerci and cause the cerci to bend dorsally. The inflated sex pheromone glands support the female cerci from the ventral side. The paired welldeveloped basal processes seize the lateral membranes of the female genital segment (figs. $5 \mathrm{~A}, \mathrm{~B}$ ).

The genital coupling of $N$. lui is almost identical with that of $N$. carpenteri (supplementary fig. S2).

The basal processes of $N$. longiprocessa gonostyli grasp the posterior portion of the female medigynium across the lateral membranes from the ventral side (fig. $5^{\mathrm{C}}$ ). On the dorsal side, the basal processes seize the female subgenital plate to allow the intersegmental membrane of abdominal segments VIII and IX to be narrowed (fig. $5 \mathrm{D}$ ).

The male aedeagus and female medigynium of $N$. lui physically couple with each other (figs. $5 \mathrm{E}, \mathrm{F}$ ). The acute lateral processes of the aedeagus support the prolonged posterior arms of the medigynium from the ventral side. The well-developed ventral valves touch the middle portion of the medigynium to allow the male phallotreme to connect to the female copulatory pore (figs. $5 \mathrm{E}, \mathrm{F}$ ).

The elongate ventral valves of $N$. longiprocessa also keep down the female medigynium (fig. 6A). The lateral processes of the aedeagus couple with the posterior arms of medigynium (figs. 6B, C). The parameres are located between the male ventral valves and the female posterior arms (fig. 6B). The basal processes firmly control the female medigynium across the intersegmental membrane of abdominal segments VIII and IX to establish a connection of the male phallotreme to the female copulatory pore (fig. 6C).

\section{Discussion}

In the present study, both male $N$. lui with a weakly-developed notal organ and male $N$. carpenteri with a medium-sized notal organ provide a salivary mass as the nuptial gift, whereas male $N$. longiprocessa with an extremely elongated notal organ continuously grasps the female wings and adopt a coercive mating tactic. Prior to providing a salivary mass, both couples of $N$. lui and $N$. carpenteri 

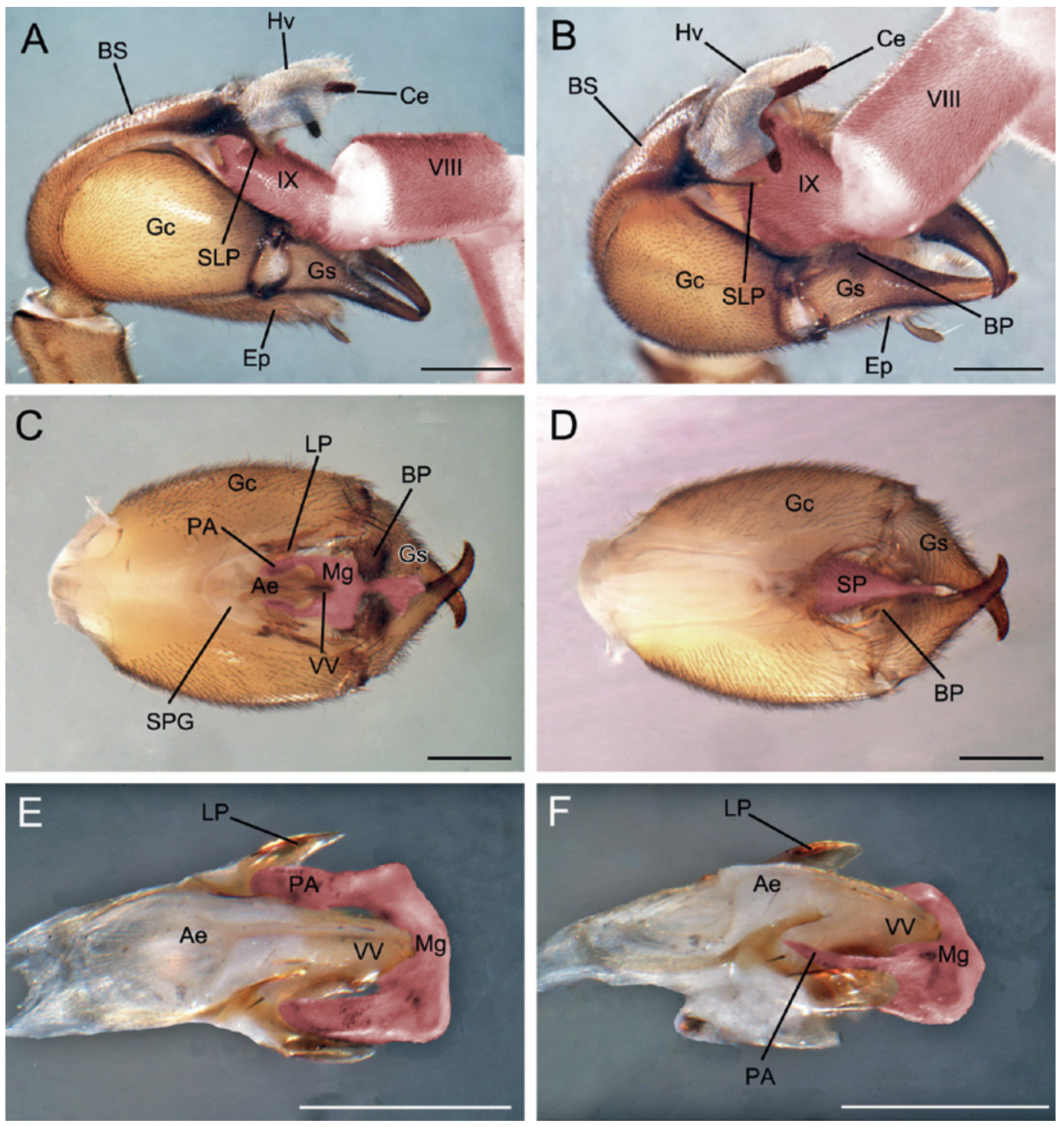

FIGURE 5 Coupling genitalia in Neopanorpa (for all, the male genital structures are situated on the left, the female on the right; terminal end of female is colored in pink). A, B, genital coupling of $N$. carpenteri to show the hypovalves control the female cerci and the basal processes grasp the female lateral membranes of the genital segments; C, D, genital coupling of $N$. longiprocessa with the epandrium and hypandrium removed to show the basal processes grasp the female medigynium and subgenital plate, and the ventral valves of aedeagus keep down the female medigynium; E, F, simulating copulation of the female medigynium and the male aedeagus of $N$. lui to show the ventral valves of the aedeagus keep down the female medigynium. Ae, aedeagus; BP, basal process; BS, basal stalk; Ce, cercus; Ep, epandrium; Gc, gonocoxite; Gs, gonostylus; Hv, hypovalve; LP, lateral process; Mg, medigynium; PA, posterior arm; SP, subgenital plate; SLP, sclerotized lateral process; SPG, sex pheromone glands; VV, ventral valve. Scale bars $=0.5 \mathrm{~mm}$. 

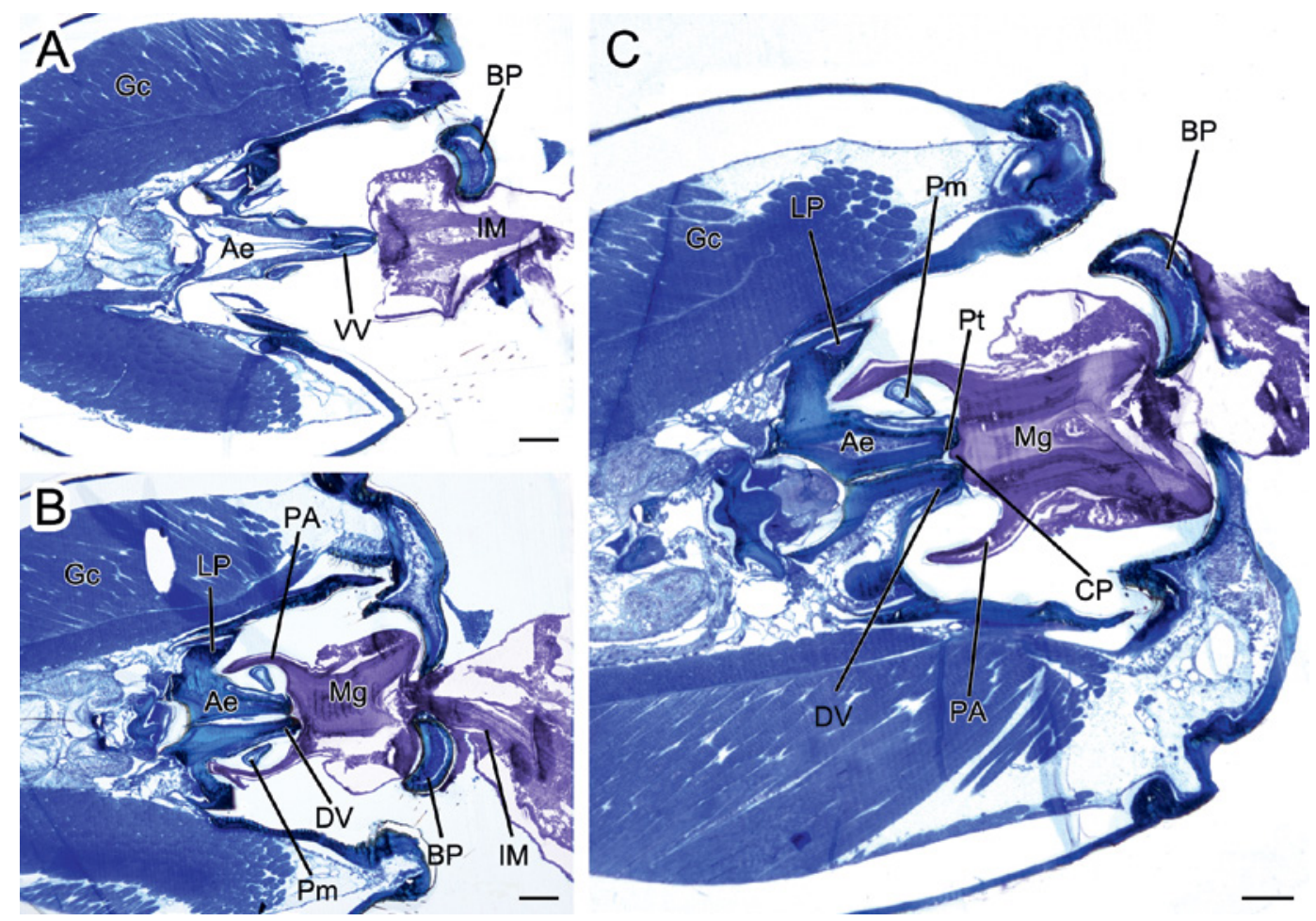

FIGURE 6 Section series of coupling genitalia of Neopanorpa longiprocessa (for all, the male genital structures are situated on the left, the female on the right; terminal end of female is colored in purple). A, ventral portion of the coupling genitalia to show the elongated ventral valves of the aedeagus; $\mathrm{B}$, median portion of the coupling genitalia to show the male basal processes grasp the female medigynium and the male aedeagus physically couples with the female medigynium; $\mathrm{C}$, the same to show the male phallotreme connects to the female copulatory pore. Ae, aedeagus; BP, basal process; $\mathrm{CP}$, copulatory pore; DV, dorsal valve; Gc, gonocoxite; Gs, gonostylus; IM, intersegmental membrane; LP, lateral process; Mg, medigynium; PA, posterior arm; Pm, paramere; Pt, phallotreme; VV, ventral valve. Scale bars = $0.1 \mathrm{~mm}$.

intermittently maintain a mouth-to-mouth mode for approximately two hours, and do not transfer any salivary secretion. This special behaviour is lacking in $N$. longiprocessa and other genera of scorpionflies (Thornhill, 1980, 1981; Thornhill \& Sauer, 1991; Sauer et al., 1998; Engqvist \& Sauer, 2001; Engles \& Sauer, 2006; Zhong \& Hua, 2013b; Zhong et al., 2015a, b; Tong et al., 2018). The genital couplings are very similar among the three species of $\mathrm{NeO}$ panorpa with notal organs of various lengths.

The hypovalves grasp the cerci of the female and move up and down rhythmically, likely to stimulate and pacify the female (Ma et al., 2010; Zhong \& Hua, 2013b; Zhong et al., 2015a, b;
Tong et al., 2018). The paired lateral processes on the male hypovalves of $N$. carpenteri may function to help the hypovalves to control the female cerci. Although the hypovalves of $\mathrm{NeO}$ panorpa are morphologically different from those of other genera (Cai \& Hua, 2008; Ma \& Hua, 2011a; Zhong \& Hua, 2013a; Gao et al. 2016; Wang \& Hua, 2018a, 2019), their function may be similar to that of Cerapanorpa, Furcatopanorpa, and Panorpa.

The well-developed basal processes on the male gonostyli of Neopanorpa firmly control the female medigynium to allow the male aedeagus to couple with the female medigynium, as in Panorpodes kuandianensis Zhong, 
Zhang \& Hua, 2011 (Tong et al., 2017). In F. longihypovalva and C. dubia (Chou \& Wang, 1981), however, the undeveloped basal processes grasp the posterior portion of the female medigynium because the female axis is elongated (Zhong et al., 2015b; Tong et al., 2018). The ventral valves of the male aedeagus of Neopanorpa are longer than those of $C$. dubia (Gao et al., 2016; Tong et al., 2018) and also function to keep down the female medigynium. Therefore, the female medigynium of Neopanorpa can be ventrally controlled by the ventral valves of the aedeagus, seized dorsally and anteriorly by the basal processes. The males of Neopanorpa may control the female medigynium more firmly than other genera of Panorpidae.

The mouth-to-mouth behaviour is an interesting phenomenon in insect mating process. Some social insects (such as bees, ants and wasps) pass food to one another through a mouth-to-mouth trophallaxis (Korst \& Velthuis, 1982; Suryanarayanan \& Jeanne, 2008; Hamilton et al., 2010). In Mecoptera, the males of Chorista (Choristidae) and Furcatopanorpa (Panorpidae) transfer liquid salivary secretions through a mouth-to-mouth mode during mating (Byers \& Thornhill, 1983; Zhong et al., 2015b). In N. lui and N. carpenteri the males and females connect their mouthparts to each other prior to copulation but do not transfer any edible food. It is difficult for us to support the hypothesis that Neopanorpa female stimulates the male to secrete a nuptial gift through a mouth-to-mouth mode, because the male of $N$. setigera Wang \& Hua, 2018 with a greatly elongate notal organ also has the mouth-to-mouth behaviour during the seizing phase but lacks nuptial feeding (supplementary fig. $\mathrm{S}_{3}$ ) as in $N$. longiprocessa. We infer that Neopanorpa males may stimulate and pacify the female through the connection of the mouthparts to benefit them to obtain copulation.
In Mecoptera the nuptial feeding behaviour is widespread in Panorpidae, Panorpodidae, Bittacidae, and Choristidae (Byers \& Thornhill, 1983; Sauer et al., 1998; Engqvist \& Sauer, 2003; Gao \& Hua, 2013; Zhong et al., 2015a, b; Tong et al., 2017). It is regarded to help the male scorpionflies to attract a female and prolong the copulation duration (Sauer et al., 1998; Engqvist \& Sauer, 2003; Zhong et al., 2015a). The only reported species lacking a nuptial feeding behaviour during mating in Neopanorpa is N. longiprocessa, whose elongated notal organ can seize the female's wings for approximately two hours to coercively mate with the female (Zhong \& Hua, 2013b). During this process, however, an intense physical conflict arises in the male and the female of $N$. longiprocessa. In the present study, the males of $N$. lui and $N$. carpenteri obtain copulation soon afterwards when they secrete a salivary mass. The female shows little resistance when she begins to feed on the nuptial gift. Our results may support the hypothesis that the nuptial feeding behaviour benefits male scorpionflies to obtain copulation easily and reduce the resistance of the female. However, our data hardly provide any evidence that the nuptial gift can prolong copulation, because the copulation duration of three species of Neopanorpa have no significant differences.

The insects' glands associated with nuptial feeding behaviours show a diversity according to their various abilities to secrete a nuptial gift, such as the accessory glands of dobsonflies and the salivary glands of scorpionflies (Byers \& Thornhill, 1983; Hayashi, 1992; Ma \& Hua, 2011b; Ma et al., 2011; Liu et al., 2015). The male dobsonflies of $\mathrm{Neo}$ neuromus, Nevromus, Neurhermes, and Protohermes can provide larger spermatophores as nuptial gifts due to their well-developed accessory glands (Hayashi, 1992; Liu et al., 2015). The male scorpionflies of Furcatepanorpa, Dicerapanorpa, Cerapanorpa, and most 
Panorpa can offer abundant salivary secretions as nuptial gifts corresponding to their elongated multi-furcated salivary glands (Potter, 1938; Ma et al., 2011; Zhong et al., 2015b).

The males of $P$. liui and $N$. longiprocessa fail to provide any salivary secretions as a nuptial gift because their salivary glands are very short and only extend to the prothorax (Ma \& Hua, 2011b; Ma et al., 2011). In N. lui and N. carpenteri the males offer salivary masses to the female during mating. Although their salivary glands are also bifurcated, they are elongated to the abdominal segment V or VI. The male of $N$. carpenteri can produce larger salivary mass than the male of $N$. lui because its salivary glands are more developed and longer than the latter. Our results may provide additional evidence to support the hypothesis that the developmental degree of the secretory glands may correspond to a male's ability to produce the salivary secretions as the nuptial gift.

The notal organs of various lengths function to seize the wings of female scorpionflies to enhance the male control of copulation (Thornhill \& Sauer, 1991; Kock et al., 2009; Zhong \& Hua, 2013b). However, only in Neopanorpa with an extremely elongated notal organ can the male firmly grasp the female to primarily adopt a forced mating tactic. The male with a weakly-developed or mediumsized notal organ probably has to evolve a nuptial feeding behaviour to attract the female to obtain copulation with ease. We summarize the lengths of the notal organs of 32 species of Neopanorpa in supplementary table $\mathrm{S} 1$, according to the phylogenetic tree presented by Miao et al. (2019). Most notal organs of $\mathrm{NeO}$ panorpa males are short. Only a few males bear the extremely elongated notal organs and they are marked in supplementary fig. $\mathrm{S}_{4}$. It is necessary to add ancestral reconstruction analysis for future studies to assess the evolution of the notal organ lengths and the mating tactic of Neopanorpa.

\section{Acknowledgements}

We are grateful to Ji-Shen Wang, Xiao-Yan Wang, Kai Gao, and Zheng Wei for help in the specimen collection. We also thank PengYang Wang and Mei-Zhuo Jia for assistance in taking care of the adults and copulation observation. We appreciate Gui-Lin $\mathrm{Hu}$ and Wei Du for providing a live photo of Neopanorpa setigera in copulation and the information on the mating behaviour. We also thank Ying Miao for comments on the early draft of the manuscript. Special thanks to the two anonymous reviewers for valuable comments on the revision of the manuscript. The research was supported by the National Natural Science Foundation of China (Grant no. 31672341).

\section{Supplementary material}

Supplementary material is available online at: https://doi.org/10.6o84/mg.figshare.9192470

\section{References}

Boggs, C.L. (1990) A general model of the role of male-donated nutrients in female insects' reproduction. Am. Nat., 136, 598-617.

Byers, G.W. \& Thornhill, R. (1983) Biology of the Mecoptera. Annu. Rev. Entomol., 28, 203-228.

Cai, L.J., Huang, P.Y. \& Hua, B.Z. (2008) Sinopanor$p a$, a new genus of Panorpidae (Mecoptera) from the Oriental China with descriptions of two new species. Zootaxa, 1941, 43-54.

Cheng, F.Y. (1949) New species of Mecoptera from northwest China. Psyche, 56, 139-173.

Cheng, F.Y. (1957) Revision of the Chinese Mecoptera. Bull. Mus. Comp. Zool., 116, 1-117.

Chou, I., Ran, R.B. \& Wang, S.M. (1981) Taxonomic studies on the Chinese Mecoptera (I, II). Entomotaxonomia, 3, 1-18. 
Engels, S. \& Sauer, K.P. (2006) Resource-dependent nuptial feeding in Panorpa vulgaris: an honest signal for male quality. Behav. Ecol., 17, 628-632.

Engqvist, L. (2007) Sex, food and conflicts: nutrition dependent nuptial feeding and pre-mating struggles in scorpionflies. Behav. Ecol. Sociobiol., $61,703-710$.

Engqvist, L. (2009) Should I stay or should I go? Condition- and status-dependent courtship decisions in the scorpionfly Panorpa cognata. Anim. Behav., 78, 491-497.

Engqvist, L. \& Sauer, K.P. (2001) Strategic male mating effort and cryptic male choice in a scorpionfly. P. Roy. Soc. B-Biol. Sci., 268, 729-735.

Engqvist, L. \& Sauer, K.P. (2003) Influence of nutrition on courtship and mating in the scorpionfly Panorpa cognata (Mecoptera, Insecta). Ethology, 109, 911-928.

Gao, Q.H. \& Hua, B.Z. (2013) Co-evolution of the mating position and male genitalia in insects: a case study of a hangingfly. PLoS ONE, 8, e80651.

Gao, C., Ma, N. \& Hua, B.Z. (2016) Cerapanorpa, a new genus of Panorpidae (Insecta: Mecoptera) with descriptions of three new species. Zootaxa, 4158, 93-104.

Gwynne, D.T. (2008) Sexual conflict over nuptial gifts in insects. Annu. Rev. Entomol., 53, 83-101.

Hamilton, C., Lejeune, B.T. \& Rosengaus, R.B. (2010) Trophallaxis and prophylaxis: social immunity in the carpenter ant Camponotus pennsylvanicus. Biol. Lett., 7, 89-92.

Hayashi, F. (1992) Large spermatophore production and consumption in dobsonflies Protohermes (Megaloptera: Corydalidae). Jpn J. Entomol., 6o, 59-66.

Hua, B.Z. (1997) A new species of the genus Panorpa (Mecoptera: Panorpidae) from northeast China. Entomotaxonomia, 19, 213-215.

Hua, B.Z. \& Chou, I. (1997) The Panorpidae (Mecoptera) of Funiu Mountain in Henan Province. Entomotaxonomia, 19, 273-278.

Jiang, L. \& Hua, B.Z. (2015) Morphological comparison of the larvae of Panorpa obtusa Cheng and Neopanorpa lui Chou and Ran (Mecoptera: Panorpidae). Zool. Anz., 255, 62-70.

Kock, D., Engels, S., Fritsche, C. \& Sauer, K.P. (2009) Sexual coercion in Panorpa scorpionflies? The function of the notal organ reconsidered. Behav. Ecol., 20, 639-643.

Kock, D., Ruther, J. \& Sauer, K.P. (2007) A male sex pheromone in a scorpionfly. J. Chem. Ecol., 33, 1249-1256.

Korst, P.J.A.M. \& Velthuis, H.H.W. (1982) The nature of trophallaxis in honeybees. Insect. Soc., 29, 209-221.

Krzemiński, W. \& Soszynska-Maj, A. (2012) A new genus and species of scorpionfly (Mecoptera) from Baltic amber, with an unusually developed postnotal organ. Syst. Entomol., 37, 223-228.

Lehmann, G.U.C. (2012) Weighing costs and benefits of mating in bushcrickets (Insecta: Orthoptera: Tettigoniidae), with an emphasis on nuptial gifts, protandry and mate density. Front. Zool., 9, 19.

Lewis, S. \& South, A. (2012) The evolution of animal nuptial gifts. Adv. Stud. Behav., 44, 53-97.

Linnaeus, C. (1758) Systemae naturae per regna tria naturae, secundum classes, ordines, genera, species, cum characteribus, differentiis, synonymis, locis. Holmiae (Stockholm), Laurentii Salvii.

Liu, X.Y., Hayashi, F., Lavine, L.C. \& Yang, D. (2015) Is diversification in male reproductive traits driven by evolutionary trade-offs between weapons and nuptial gifts? P. Roy. Soc. B-Biol. Sci., 282, 20150247.

Ma, N. \& Hua, B.Z. (2011a) Furcatopanorpa, a new genus of Panorpidae (Mecoptera) from China.J. Nat. Hist., 45, 2251-2261.

Ma, N. \& Hua, B.Z. (2011b) Structural evidence why males of Panorpa liui offer prey rather than salivary mass as their nuptial gift. Acta Zool., 92, 398-403.

Ma, N., Liu, S.Y. \& Hua, B.Z. (2011) Morphological diversity of male salivary glands in Panorpidae (Mecoptera). Eur.J. Entomol., 108, 493-499.

Ma, N., Zhong, W. \& Hua, B.Z. (2010) Genitalic morphology and copulatory mechanism of 
the scorpionfly Panorpa jilinensis (Mecoptera: Panorpidae). Micron, 41, 931-938.

Miao, Y., Wang, J.S. \& Hua, B.Z. (2019) Molecular phylogeny of the scorpionflies Panorpidae (Insecta: Mecoptera) and chromosomal evolution. Cladistics, 35, 385-400.

Mickoleit, G. (1971) Zur phylogenetischen und funktionellen Bedeutung der sogenannten Notalorgane der Mecoptera (Insecta, Mecoptera). Z. Morphol. Tiere, 69, 1-8.

Preston-Mafham, K.G. (1999) Courtship and mating in Empis (Xanthempis) trigramma Meig., E. tessellate F. and E. (Polyblepharis) opaca F. (Diptera: Empididae) and the possible implications of 'cheating' behavior. J. Zool., 247, 239-246.

Potter, E. (1938) The internal anatomy of the order Mecoptera. Trans. R. Entomol. Soc. Lond., 87, 467-501.

Sauer, K.P., Lubjuhn, T., Sindern, J., Kullmann, H., Kurtz, J., Epplen, C. \& Epplen, J.T. (1998) Mating system and sexual selection in the scorpionfly Panorpa vulgaris (Mecoptera: Panorpidae). Naturwissenschaften, 85, 219-228.

Stutt, A.D. \& Siva-Jothy, M.T. (2001) Traumatic insemination and sexual conflict in the bed bug Cimex lectularius. P. Natl. Acad. Sci. USA, 98, $5683-5687$.

Suryanarayanan, S. \& Jeanne, R.L. (2008) Antennal drumming, trophallaxis, and colony development in the social wasp Polistes fuscatus (Hymenoptera: Vespidae). Ethology, 114, 1201-1209.

Thornhill, R. (1980) Rape in Panorpa scorpionflies and a general rape hypothesis. Anim. Behav., 28, $5^{2-59 .}$

Thornhill, R. (1981) Panorpa (Mecoptera: Panorpidae) scorpionflies: systems for understanding resource-defense polygyny and alternative male reproductive efforts. Annu. Rev. Ecol. Syst., $12,355-386$.

Thornhill, R. (1992) Female preference for the pheromone of males with low fluctuating asymmetry in the Japanese scorpionfly (Panorpa japonica: Mecoptera). Behav. Ecol., 3, 277-283.
Thornhill, R. \& Alcock, J. (1983) Evolution of Insect Mating Systems. Harvard University Press, Massachusetts.

Thornhill, R. \& Sauer, K.P. (1991) The notal organ of the scorpionfly (Panorpa vulgaris): an adaptation to coerce mating duration. Behav. Ecol., 2, 156-164.

Tong, X., Jiang, L. \& Hua, B.Z. (2017) A unique mating pattern of Panorpodes kuandianensis (Mecoptera: Panorpodidae). Contrib. Zool., 86, 229-237.

Tong, X., Zhong, W. \& Hua, B.Z. (2018) Copulatory mechanism and functional morphology of genitalia and anal horn of the scorpionfly Cerapanorpa dubia (Mecoptera: Panorpidae).J. Morphol., 279, 1532-1539.

Tong, X. \& Hua, B.Z. (2019) The sperm pump and genital coupling of Panorpodes kuandianensis (Mecoptera: Panorpodidae). Arthropod Struct. Dev., 50, 15-23.

Vahed, K. (1998) The function of nuptial feeding in insects: a review of empirical studies. Biol. Rev., $73,43-78$.

Vahed, K., Gilbert, J.D.J., Weissman, D.B. \& Barrientos-Lozano, L. (2014) Functional equivalence of grasping cerci and nuptial food gifts in promoting ejaculate transfer in katydids. Evolution, 68, 2052-2065.

van der Weele, H.W. (1909) Mecoptera and Planipennia of Insulinde. Notes Leyden Mus., 31, 1-100.

Wang, J.S. \& Hua, B.Z. (2019a) Megapanorpa, a new genus with a single anal horn in males from Oriental China (Mecoptera: Panorpidae). Entomol. Sci., 22, 64-79.

Wang, J.S. \& Hua, B.Z. (2019b) A Color Atlas of the Chinese Mecoptera. Henan Science and Technology Press, Zhengzhou.

Wang, M. \& Hua, B.Z. (2018a) A new species of Neopanorpa with an extremely long notal organ from Sichuan, China (Mecoptera, Panorpidae). ZooKeys, 750, 131-140.

Wang, M. \& Hua, B.Z. (2018b) High species diversity of the genus Neopanorpa (Mecoptera, 
Panorpidae) in Yunnan Province, China. Zootaxa, 4483, 36-66.

Wang, Z. \& Hua, B.Z. (2018c) Ultrastructure of the single-chamber stemmata of Arge pagana (Panzer, 1798) (Hymenoptera: Argidae). Arthropod Struct. Dev., 47, 614-621.

Zhong, W. \& Hua, B.Z. (2013a) Dicerapanorpa, a new genus of East Asian Panorpidae (Insecta: Mecoptera: Panorpidae) with descriptions of two new species. J. Nat. Hist., 47, 1019-1046.

Zhong, W. \& Hua, B.Z. (2013b) Mating behaviour and copulatory mechanism in the scorpionfly
Neopanorpa longiprocessa (Mecoptera: Panorpidae). PLoS ONE, 8, e 74781.

Zhong, W., Ding, G. \& Hua, B.Z. (2015a) The role of male's anal horns in copulation of a scorpionfly. J. Zool., 295, 170-177.

Zhong, W., Qi, Z.Y. \& Hua, B.Z. (2015b) Atypical mating in a scorpionfly without a notal organ. Contrib. Zool., 84, 305-315.

RECEIVED: 25 APRIL 2019 | REVISED AND ACCEPTED: 30 JULY 2019

EDITOR: R. VONK 